that the endocarditis of acute rheumatism is much more widely spread than appears by a naked-eye inspection;" and proceeds thus to describe some of the microscopic changes referred to: "The whole tissue of the valves is swollen; it is seen under the microscope to have lost its normal fibrous appearance and to be infiltrated with cellular elements." Wherein does that sentence differ from the following one taken from page 137 of my book: "The inflammatory process which takes place in the valvular fibrous tissue gives rise to multiplication of its cellular elements, and consequent thickening of the valve." The two sentences are so like each other, and so exactly describe the sume morbid change, that they might be transposed. The chief difference between them is that mine was written in 1881 and Dr. Sansom's in 1883. Continuing the subject, he says, "The inflammation, moreover, is not confined to the endocardium, the exudation spreads to, and infiltrates, the muscular structure to which the valves and the tendinous cords are attached, and even the root of the aorta." Here, again, Dr. Sansom is treading in my footsteps. If he will refer to the chapters in my book bearing on the subject, he will find much on the subject of rheumatic inflammation of the muscles and fibrous rings, including the root of the aorta. Out of consideration for your space I satisfy myself with two brief quotations: "The fibrous rings are a common seat of rheumatic inflammation" (page 162). "The muscular substance is frequently involved in the morbid process" (page 165), to which $\mathrm{I}$ would add one extract from $\mathrm{my}$ former letter to you: "The parts which suffer in the heart are the fibrous rings and valves, the endo- and peri-cardial linings, and occasionally the muscular substance."

I think I have said enough to show that Dr. Sansom and $I$ are not so much at variance as would appear from lhis letter, and that many of the morbid changes which he describes had already been described by me two years before his lectures were delivered. But though agreed as to the nature and extent of the changes which take place, we differ materially in our views as to their mode of production. Dr. Sansom regards the endocardial lining membrane as the primary seat of rheumatic inflammation, and "the beadike elevations on the surface or borders of the valves but a the concomitants of an extensively diffused inflammation." But if that be so, why do they occur only on the valves and why only on one surface of a valve? Why is it that they are always on the same surface? And why is this surface in the aortic valve always its convex, and in the mitral always its auricular? There must be a reason for this limitation of the bead-like elevations to these particular portions of the endocardial surface. The friction theory supplies an adequate reason if we only admit a prior thickening of the valve such as both Dr. Sansom and I have described. When Dr. Sansom says, "I cannot therefore accept the friction theory as accounting for rheumatic endocarditis," he conveys the impression that I do accept it as accounting for that disease. In doing so he ought to have known that he is attributing to me views which I do not hold. I have distinctly said that friction is not the cause of rheumatic endocarditis, but a mere incident (though an important one) occurring at a certain stage of that disease. It causes not the endocarditis, but only the roughening of the valvular surface, and it comes into play only after the rheumatic inflammation is established, and the fibrous texture of the valve is already swollen from cellular infiltration. This view of the matter Dr. Sansom seems to have been dimly conscious of ; for he adds, in an apologetic sort of manner : ... " though friction may well be a cause determining the aggregation of cellular elements at certain spots of the endocardium, the formation of beads and the deposit on the devitalised surfaces of the little caps of fibrine with which we are familiar." Why, Sir, that is just what I have said that friction does, exactly the rôle which I have attributed to it, and I am glad to find Dr. Sansom coming round, even though reluctantly, to my view of the matter. But here I must point ont the grave pathological error in to which Dr. Sansom has fallen, an error which is at the foundation of all the difference between us. In considering the pathology of rheumatic endocarditis it is essential that we should distinguish between the changes which take place in the endocardial lining membrane and those noted in the fibrous texture of the rings and valves. This Dr. Sansom has failed to do. He accurately enough describes the changes which take place both in the deeper fibrous structure of the valve and in its superficial endocardial covering; but he has failed to recognise that these two structures are essentially different both in nature and function, and that the bead-like elevations which are formed on the surface differ entirely in their mode of production, and in their formation, from the changes which take place in the deeper tissue of the valve. Rheumatic endocarditis consists primarily and essentially in inflammation of the fibrous texture; the endocardial lining becomes involved only secondarily, and after the valves have become swollen from cellular infiltra. tion of their fibrous structure. "The swelling it is which makes the valves rub, and the rubbing it is which irritates and roughens the membrane which covers them externally." Both physiologically and pathologically the endocardial lining is to be regarded as pertaining to the vascular canals rather than to the heart. It has no vessels ; in the absence of these it cannot be, and as a matter of fact never is, the seat of spreading inflammation. It may be irritated, and even have a hole rubbed through it, by a valvular vegetation; but the mischiet is confined to the one spot, and never causes such general inflammation as would result from a similar agency acting on the vascular pericardium, If it cannot itself be the seat of primary inflammation, it is im. possible for it to be a source of secondary inflammation in continuous tiseues. Rheumatic inflammatory disturbance originating in filbrous or muscular structures of the heart may extend to and iojure the endocardial lining, and generally does so more or less ; but the process is never reversed. But the question has more than a pathological interest. In the vast majority of cases in which the heart is permanently damaged in acute rheumatism, the damage essentially consists in injury to the endocardial lining. As I said in my former letter, "The inflammation and thickening of the fibrous structure of the valve may be recovered from. What is not recovered from is the roughening of and lymphy deposit on its non-vascular endocardial covering." The former is antecedent to and causative of the latter. If the former can be prevented, or arrested early, the latter will not be developed, and the heart will not be damaged. We know that by the free administration of the salicyl compounds we can arrest and prevent rheumatic inflammation of the fibrous textures of a joint. The fibrous textures of the heart are identical in nature and function with those of the joints; like them, they are subject to rheamatic inflammation. May they not also, like them, have that inflammation arrested and prevented by the free ad. ministration of the salicyl compounds? But to get this result in the heart, we must see the case early, before the valves are so swollen that they begin to rub from premature con. tact. That, of course, is the difficulry; but it is as certain as such a thing can be that some such chances do occur; and I am glad to note Dr. Sansom's assurance that he intends to adopt my plan of giving, not salicylate of soda which cannot safely be given in large doses, but salicin. Let me beg him, and those who may follow his example, to give, as I recommend, thirty grains every hour. But letme beg him and them also to bear in mind that the morbid process which the salicin can arrest and prevent is the primary rheumatic inflammation of the deeper-seated fibrous structure of the valve, and not the secondary mechanical irritation and roughening of its endocardial covering.

I am, Sir, your obedient servant,

Cadogan-place, March, 1883.

T. J. MACLAGAN.

\section{FOOT-AND-MOUTH DISEASE AND THE LYING-IN WOMAN.}

\section{To the Editor of THE LANCET.}

SIR, - I have recently seen in consultation a case of fatal metria. On inquiry, I found that the patient had been sup. plied with milk from a farm where foot-and-mouth disease was widely prevalent. All other causes of zymotic or septic poisoning were apparently capable of being eliminated; and though there was fetid lochial discharge, a careful investigation of the uterine cavity discovered nothing, and repeated washings of its interior produced no favourable results on the temperature, so that one may set aside what Duncan terms sapremia. 'The sanitary surroundings of the house were also excellent.

I should like very much to know whether any of your readers have met with or suspected foot-and-mouth disease as a cause of material blood-poisoning. There is little doubt 
that everyone of the human infectious diseases may give rise to the symptoms of the so-called puerperal fever in the lying-in woman; and, reasoning by analogy, one wou'd expect the same from the bovine aifection. Yet surely in that case there should always be numerous recorded instances. The lady's friends naturally expect a positive answer to the question, May the milk of cows thus affected produce these results? I can only answer provisionally, that I think it entirely probable. In that district, several miles from Manchester, where the case occurred, there is a wide prevalence of foot-and-mouth disease, and with the greatest care on the part of the farmers there would still be a source of extreme danger to the lying-in woman there.

As the matter now stands I would certainly advise that no milk should be used by the lying-in woman in such a district, certainly none that had not been subjected to boiling.

If any corroborative cases have been published I have missed or overlooked them.

I am, Sir, yours, \&e,

J. Thorburn, M.D.

Bianchester, March 12 th, 1883 . Professor of Obstetric Medicine, Victoria University.
Tarch 12th, 1883 .

\section{"THE OPINION OF A 'DENTAL SURGEON." To the Editor of THE LANCET.}

StR,-I feel certain that any unbiassed person who read my first letter to you, elicited by an annotation in your journal which, unintentionally, seemed to class the qualifiea and unqualified in my speciality together, would see that it was animated by a desire to uphold the social and scientific position of a branch of surgery as much entitled to recognition as any other when legitimately and honourably practised. It is remarkable that those who profess to reply to it impute opinions to me which I have never held, much less expressed, whilst they corroborate my statements. Their resort to personalities is regrettable, as my communication referred to measures, not persons. Such weapons procliaim a weak cause, and never strengthen argument.

My contentions were :-First, that it was unjust to the whole medical profession that wholly unqualified persons should be permitted to call themselves surgenns, or even dental surgeons. Secondly, that the Dental Registration Bill had permitted individuals of the lowest type to register themselves as dentists when such an excellent opportunity presented itself of purifying the profession by purging it of persons not carrying on their business -I will not say their profession-in a reputable manner. How do my critics answer these propositions? Simply by assenting to them! The first writer commences by a totally irrelevant attack upon the Association of Surgeons Practising Dental Surgery, which was founded for a special purpose, and which, despite his assertions, is by no means effete, and then enters npon a prolix digression on matters to which I did not even allude. I never denied that if we wait long enough-tout vient à qui sait attendre,benefit may result from the Act in the far future; but I maintained that proper means had not been taken by the promotors of the Bill to prevent the registration of those who are an opprobrium to any liberal profession, mentioning the fact that shops existed over the disgusting show cases of which the owners advertised themselves as "registered dental surgeon," or even " registered surgeon and dentist." Your three correspondents unanimously accept these asser tions. The first writer says: "It is undeniable that there are undesirable registered dentists"; while he cannot deny the existence of the shops which have indubitably increased threefold since that "disastrous"-I never said "monstrous" - legislation which has so degraded the present status of dental surgery. Prior to the passing of the Act, their proprietors were outside the pale of professional respectability. Now they find a legal sanction. This correspondent assumes that I am opposed to the dental licentiateship; whereas, had he read my letter, he would have seen that I expressly stated that "I did not allude to those who hold the dental licence of the College of Surgeons." And assuredly, had the Bill required unqualified practitioners to become licentiates, or had it only admitted, after careful selection, those who conducted their practices honourably to registration, there are few, certainly not myself, who would not have supported such healthy legislation. Thus, the letter I am criticising, being based upon false premises, must result in false conclusions; indeed, it is hard to magine the object with which it, was written, inasmuch as, whilst it most inexcusably misrepresents my views, it supports my contention and confirms my propositions. The author of the second letter somewhat more courteously assumes my ignorance of the provisions of the Act, but admits that the "inferior practitioners" recognised by it have no right to assume "the title of surgeon or surgeondentist," whilst even Mr. Cox (of whose existence, if he will pardon me for saying so, I had never heard until I read his communication of to-day) confesses that he is "as much disgusted with the admission of an indiscriminate host as the "professor' (sic) himself." I very much regret that inasmuch as he is so particular in emphasising my legitimate title I should have done him the injustice of depriving him of his, especially as he is in accord with me as to the impropriety of admitting unqualified empirics to equal privileges with those who are generally or specially qualified. Finally, with regard to the sentiments which render me too sensitive, perhaps, about the social position of my speciality in surgery, I leave their interpretation to my friends who know me, not to those with whom I am not acquainted.

The suggestion that those who sympathise with me assume pre-emineuce on account of their possession of a medical diploma is ridiculous as it is uncalled for, though I frankly confess that $I$ am ashamed to be associated, even in name, with many of those whom recent legislation has permitted to register themselves as "dental surgeons." Here a medical qualification does afford protection. My opponents seem to forget the trite motto "Quot homines, tot sententix." In upholding my own opinions I should never be so illiberal as to quarrel with them for having theirs, however much they might be opposed to mine.

I am, Sir, your obedient servant,

S. HAMILTON CARTWRIGHT,

Professor of Dental Surgery to King's College, and Dental Surgeon to King's College Hospital.

Old Burlington-street, March 16th, 1883.

\section{"THE FUNCTIONS OF THE SEMICIRCULAR CANALS."}

To the Editor of THE LANCET.

SIn,-In your issue of February 17 th last there appeared an interesting leader on the above subject, in which you drew attention to certain experiments of M, Vulpian. In a subsequent number of your journal there likewise appeared a letter from Mr. Dalby, very cogently arguing against the assumption of the semicircular canals being specially influenced in the experiments referred to, and relating certain facts commonly to be observed in aural practice. It is a frequent habit among physiological experimenters, and one introducing a very considerable element of fallacy in their conclusions, to regard animals as mere automata, and wholly to attribute to some local, it may be central, irritation or stimulus any and every peripheral manifestation, with out taking sufficiently into consideration the element of intention or mind in the lower animal.s. It is not, however, to reite rate Mr. Dalby's objections that I presume to trespass on your valuable time and space, but to emphasise the importance yon very justly attribute to the phenomenon of "sympathetic" irritation of tise ear opposite to that operated upon, observed in one of M. Vulpian's experiments, and which is, I believe, not only explanatory in a measure of some pathological conditions, but also capable in some cases of therapeutic application, on the principle of what may be termed the establishment of equivibration.

Some time ago I suffered from right external otitis, for which I used a lotion of lead, glycerine, and rose-water, with the result of forming an amalgam of these substances on the right membrana tympani, and causing deafness, a feeling of capital ayymmetry, or unequal sensation in the two halves of the head, the affected side being duller and heavier than the other, while a minor degree of nausea, dependent on these conditions, was likewise present. I was surprised to find that all my discomfort, except the deafness, could be removed by my plugging the sound ear with cotton. wool. This result was attributable either to the stimulation of the cutaneous nerves in the anditory canal, to the production of a certain amount of deafness in the unaffected ear, or to these conditions combined; in any case, in 